\title{
JUSTICIA ALTERNATIVA EN MATERIA AMBIENTAL
}

\author{
ALTERNATIVE JUSTICE IN ENVIRONMENTAL MATTERS
}

$$
\text { Judith Andrea Cruz-López }{ }^{*} \text { (D). }
$$

1. Escuela Judicial del Estado de Tabasco, México. winning1_9@hotmail.com

* Autor de correspondencia: Judith Andrea Cruz-López, correo electrónico: winning1_9@hotmail.com

\section{RESUMEN}

La justicia alternativa es un acceso a la justicia auto compositiva en donde el diálogo y comunicación representan toma de decisiones para el bien individual y colectivo. Ante situaciones de conflicto de interés en materia ambiental (ejidos, agua, suelo, entre otros) la toma de decisiones debe nacer desde el consenso de los que de forma directa impacta el daño ambiental (acción u omisión) en conjunto con las autoridades competentes de la materia. Para ello, las técnicas y herramientas que proporcionan los mecanismos alternativos afianzan procesos de conflictos que puedan ser gestionados y solucionados de forma participativa e inclusiva. Es de reconocer que el Estado mexicano dentro de su competencia legislativa ha proclamado y establecido leyes de manera progresiva en cuanto la integración de la justicia alternativa en conflictos de materia ambiental.

Palabras clave: criminología; sistema de justicia; víctima.

Cómo citar:

Cruz-López, Judith Andrea. (2021). Justicia alternativa en materia ambiental. Revista de Investigaciones Universidad del Quindio, 33(S2), 207-212. https://doi.org/10.33975/riuq. vol33nS2.633 


\begin{abstract}
Alternative justice is an access to self-compositional justice where dialogue and communication represent decision-making for the individual and collective good. In situations of conflict of interest in environmental matters (ejidos, water, soil, among others), decision-making must be born from the consensus of those who directly impact the environmental damage (action or omission) in conjunction with the competent authorities of The matter. For this, the techniques and tools provided by alternative mechanisms strengthen conflict processes that can be managed and resolved in a participatory and inclusive way. It is to be recognized that the Mexican State within its legislative competence has progressively proclaimed and established laws regarding the integration of alternative justice in environmental conflicts.
\end{abstract}

Keywords: criminology; justice system; victim.

\title{
INTRODUCCIÓN
}

En una sociedad compleja en el que las acciones o conductas de diferencia (Bolaños et al., 2015), violencia y conflicto son cada vez más inquietantes entre las personas, se requiere velar por mecanismos que garanticen aspectos trascendentales en la conducta de los sujetos.

Ante ello, la justicia alternativa a través de los mecanismos alternativos de solución de conflictos, nos presentan herramientas y técnicas que permiten una mejor relación de diálogo y comunicación entre las personas.

Los contextos en los que emergen las diferencias o conflictos recaen en diversos escenarios e índoles, ejemplo de ello, es el interés de este documento en materia ambiental.

En México, se prevén los mecanismos alternativos en materia ambiental para la reparación del daño, pero también señala la inclusión y participación de la ciudadanía en la toma de decisiones. Bajo ese enfoque la justicia alternativa se agota como vía de gestión y solución pacífica (Silva, 2020).

Por ello, este documento describe algunos criterios vinculados de la justicia alternativa en materia de justicia ambiental para otorgar un panorama de su proceso de aplicación y máximo aprovechamiento.

\section{METODOLOGÍA}

El medio ambiente hoy día presenta un deterioro, que en caso de no poner atención resultaría una catástrofe a nivel global que, sin duda, incide en todo ser vivo que habita el planeta. Los intereses de sectores privado y productivos deben ser bajo un panorama de responsabilidad social, sostenible e integral.

Bajo ese tenor, es de considerar relevante exponer algunos criterios o apuntes que pueden ser de utilidad respecto a la gestión y solución de conflictos en materia ambiental (Silva 2017), ya que las partes involucradas cubren sus intereses y necesidades. 
En esa interpretación y comprensión de la realidad, este documento está basado en un aspecto cualitativo con enfoque descriptivo y documental, en el que emplea el método exegético aplicable en el Estado mexicano.

\section{RESULTADOS}

\section{Medio ambiente}

Naciones Unidas mediante la Conferencia de Estocolmo, Suecia en 1972 define al medio ambiente como:

Conjunto de componentes físicos, químicos, biológicos y sociales capaces de ocasionar efectos directos e indirectos, en un plazo corto, mediano o largo, en los seres vivos y las actividades humanas.

Este concepto atañe aspectos sin límites ni fronteras, velando por una protección ambiental y administración de todo recurso natural.

Aunado a lo anterior, se considera el aspecto sustentable y sostenible, en ese mismo sentido, Naciones Unidas a través de la Comisión de Brundtland (1987) define al desarrollo sostenible como:

Aquel que satisface las necesidades del presente sin comprometer la habilidad de las generaciones futuras para satisfacer sus propias necesidades.

LaAgenda 2030, establece el compromiso de asegurar el desarrollo sostenible a las nuevas generaciones (Martínez et al., 2020), es tal la importancia que en materia ambiental considera ocho ejes como objetivos (agua, cambo climático, suelo, energía asequible y no contaminante, industria, ciudades y comunidades sostenibles, consumo responsable, vida submarina, ecosistemas terrestres).

En México, cuando se elevan a rango constitucional los derechos humanos, se prevé el derecho humano al medio ambiente sano y ecológicamente equilibrado, el cual está plasmado en la Constitución Política de los Estados Unidos Mexicanos Artículo cuarto, párrafo quinto el cual dispone:

Toda persona tiene derecho a un medio ambiente sano para su desarrollo y bienestar. El Estado garantizará el respeto a este derecho. El daño y deterioro ambiental generará responsabilidad para quien lo provoque en términos de lo dispuesto por la ley.

El derecho humano al medio ambiente implica un estado de bienestar y pleno desarrollo para una vida digna no sólo individual sino colectivo. Configura asumir la responsabilidad (Alfie, 2016) de acción u omisión al respecto, así como garantizar el acceso a la justicia.

La interdependencia e indivisibilidad de los derechos humanos y más del medio ambiente deben garantizar un estado de desarrollo, salud y bienestar, ante ello, velar a través del principio de prevención y precautorio (Silva, 2019) toda acción que invalide el derecho humano al ambiente sano y ecológicamente equilibrado.

El medio ambiente lo integra todo ser vivo, no debemos de olvidarnos del proceso formación continua a través de la educación formal y no formal para abatir, mitigar y prevenir, asegurar mediante las 
nuevas generaciones un medio ambiente en óptimas condiciones mediante un cambio de paradigma sostenible, transversal e integral.

\section{Justicia alternativa y medio ambiente}

La justicia alternativa a través de los mecanismos alternativos de solución de controversias (Gerónimo, 2021), como ya se ha señalado permiten el acceso a la justicia auto compositiva, es decir, aquella en que las partes involucradas en el conflicto son legitimadas, empoderadas y con base al diálogo y comunicación con apoyo de un facilitador pueden gestionar y llegar a un acuerdo de solución del conflicto.

Los mecanismos alternativos previstos en el artículo 17 Constitucional, en materia ambiental conllevan a considerar procedimientos administrativos correspondiente a delitos de gestión ambiental y delitos contra el medio ambiente.

La Ley Federal de Responsabilidad Ambiental (2013), en su Artículo segundo, inciso XII, considera:

La mediación, conciliación y los demás que permitan a las personas prevenir conflictos, o en su caso, solucionarlos, sin necesidad de intervención de los órganos jurisdiccionales, salvo para garantizar la legalidad y eficacia del convenio adoptado por los participantes y el cumplimiento del mismo.

En materia ambiental los conflictos originados son por el interés económico de los recursos naturales (Silva et al., 2021) aludiendo a aspectos sociales y culturales. Lo que implica considerar a la población del lugar, zona, comunidad, ejido, pueblo, de donde se lleve a cabo la intención de proyectos de desarrollo o en su caso resolver mediante la justicia alternativa conflictos de carácter jurídico y social que produzca daño al medio ambiente (Freeland, 2005).

La Ley Federal de Responsabilidad Ambiental, confiere el fin de procurar a través de la justicia alternativa una justicia restaurativa en la que los involucrados (víctima-ofendido e imputado) participen en equidad e igualdad en la controversia del delito. Se concibe la justicia restaurativa como un medio en el que la convivencia, comunicación es permanente y vela por el interés colectivo.

De los mecanismos previstos en la LNMASCMP se integran los siguientes:

Mediación

Artículo 21. Es el mecanismo voluntario mediante el cual los Intervinientes, en libre ejercicio de su autonomía, buscan, construyen y proponen opciones de solución a la controversia, con el fin de alcanzar la solución de ésta. El Facilitador durante la mediación propicia la comunicación y el entendimiento mutuo entre los Intervinientes. (LNMASCMP, 2014)

Conciliación

Artículo 25. Es el mecanismo voluntario mediante el cual los Intervinientes, en libre ejercicio de su autonomía, proponen opciones de solución a la controversia en que se encuentran involucrados. (LNMASCMP, 2014) 
Junta Restaurativa

Mecanismo mediante el cual la víctima u ofendido, el imputado y, en su caso, la comunidad afectada, en libre ejercicio de su autonomía, buscan, construyen y proponen opciones de solución a la controversia, con el objeto de lograr un Acuerdo que atienda las necesidades y responsabilidades individuales y colectivas, así como la reintegración de la víctima u ofendido y del imputado a la comunidad y la recomposición del tejido social. (LNMASCMP, 2014)

Es importante reconocer que para hacer funcionar de forma eficaz y eficiente los mecanismos es necesario integrar y aplicar los principios (LNMASCMP, 2014) de estos mecanismos los cuales se citan a continuación: voluntariedad, información, confidencialidad, flexibilidad y simplicidad, imparcialidad, equidad, honestidad.

Estos principios arraigan una serie de conductas de compromiso, asumir la responsabilidad de los hechos, además de resarcir el daño causado o en su caso impedir a través de la prevención y precaución, acción, conducta u omisión en perjuicio del medio ambiente.

El papel del facilitador es importante acorde, este tercero neutral e imparcial debe ser un profesional certificado que facilite el diálogo y comunicación entre las partes involucradas en el conflicto.

El papel del facilitador es confidencial y dirigirse durante el proceso con total verdad, así lograr un mayor consenso.

\section{DISCUSIÓN}

Un medio ambiente sano y ecológicamente equilibrado es un eje importante en el marco de los 17 Objetivos de Desarrollo Sostenible.

La justicia alternativa a través de los mecanismos alternativos de solución de controversias conlleva a procesos de participación ciudadana estableciendo y afianzando una relación entre los ciudadanos, instituciones y Estado.

La mediación, conciliación y justa restaurativa considera procesos de comunicación y diálogo a través de un consenso, capaz de transformar las relaciones para mejorar las condiciones de bien particular y colectivo.

Asumir como sociedad el compromiso con el medio ambiente es un reto, pero la educación formal e informal coadyuva a poder lograrlo, para ello, es necesario que los gobiernos legislen y apliquen la norma establecida considerando los instrumentos internacionales en los que el Estado mexicano es parte. Asimismo, integrar los mecanismos en los niveles educativos hace que las generaciones vayan integrando en su cotidianeidad procesos de cultura ambiental, convivencia, diálogo, corresponsabilidad, participación e inclusión en tomas de decisión para un estado de bienestar asegurando calidad de vida digna. 


\section{REFERENCIAS}

1. Alfie C., Miriam (2016). Política ambiental mexicana. Montañas de papel, ríos de tinta y pocos cambios en cuarenta años. El Cotidiano, (200),209-222

2. Bolaños Sánchez, Víctor Hugo, Ortega Garnelo, Fabiola, \& Reyes Baza, Diego. (2015). Medio ambiente, ciencia y sociedad. Andamios, 12(29), 7-14.

3. Cámara de Diputados. (2014). Ley Nacional de Mecanismos Alternativos de Solución de Controversias en Materia Penal. México.

4. Cámara de Diputados. (2013). Ley Federal de responsabilidad Ambiental. México.

5. Cámara de Diputados. (1917). Constitución Política de los Estados Unidos Mexicanos. Últimas reformas publicadas DOF 17-05-2021.

6. Freeland, Steven. (2005). Derechos humanos, medio ambiente y conflictos: Enfrentando los crímenes ambientales. Sur. Revista Internacional de Direitos Humanos, 2(2), 118-145. https:// dx.doi.org/10.1590/S1806-64452005000100006

7. Gerónimo González, Paulino, Silva Hernández, Francisca \& Martínez Prats, Germán. (2021). Mecanismos alternativos en la solución de conflictos para la construcción de una cultura de paz. Ciencias de la documentación, 7(1), 15-23.

8. Martínez Prats, G., Álvarez García, Y., Silva Hernández, F., \& Tagle Zamora, D. (2020). Environmental Taxes. Its Influence on Solid Waste in Mexico. Journal of Environmental Management and Tourism, 11(3), 755-762. doi:10.14505//jemt.v11.3(43).29

9. Naciones Unidas. (1987). Informe de la Comisión Mundial sobre el Medio Ambiente y el Desarrollo.

10. Naciones Unidas. (1972). Conferencia de las Naciones Unidas sobre el medio humano. Estocolmo.

11. Silva Hernández, Francisca, Martínez Prats, Germán, Guzmán Fernández, Candelaria \& Mapén Franco, Fabiola de Jesús. (2021). Dimensiones sociales y económicas del uso del recurso hídrico. UNAD: Colombia.

12. Silva-Hernández, Francisca. (2020). Hacia una comprensión del conflicto en justicia alternativa. Revista de Investigaciones Universidad del Quindio, 32(1), 61-65. https://doi.org/10.33975/riuq. vol32n1.435

13. Silva Hernández, Francisca. (2019). Principio de prevención y precautorio en materia ambiental. Revista Jurídica Derecho, 8(11), 93-106.

14. Silva Hernández, F. (2017). Medio ambiente sano y justicia ambiental. Perfiles de las ciencias sociales, 5(9), 182-194. 